\title{
Entrevista
}

\section{Núcleo de Estudos em Aquisição da Linguagem e Psicolinguística (NEALP)}

\author{
Cristina Name ${ }^{1}$
}

Universidade Federal de Juiz de Fora

\section{Entrevista concedida aos professores Kátia Abreu e Eduardo Kenedy}

Soletras: Quando o seu LAB foi fundado? Qual foi sua experiência em LABs de Psicolinguística anterior à fundação do LAB que coordena?

O NEALP ï Núcleo de Estudos em Aquisição da Linguagem e Psicolinguística ${ }^{2}$ ï foi oficialmente criado em 2007, mas começou a ser germinado em 2003, quando a pesquisa em psicolinguística teve início na UFJF, com a minha chegada à universidade. Em 2006, cadastramos o grupo de pesquisa no CNPq. Hoje, somos seis pesquisadoras e mais de vinte orientandos, contando IC, mestrado e doutorado.

Minha primeira experiência em um laboratório de psicolinguística foi no LAPAL, com a profa. Leticia Sicuro Corrêa, minha orientadora de doutorado. Nesse período, tive a oportunidade de fazer sanduíche no Laboratoire de Sciences Cognitives et Psycholinguistique (LSCP/EHESS, Paris, França), com Emmanuel Dupoux e Anne Christophe. A partir dessa experiência, participei da implantação do babylab no LAPAL, trazendo para o Brasil a técnica de Escuta Preferencial, usada em pesquisas com bebês.

Soletras: Quais os principais temas de pesquisa que seu LAB vem contemplando ao longo dos anos?

As pesquisas no NEALP se desenvolvem em duas grandes áreas da Psicolinguística: processamento adulto e aquisição de língua/linguagem. Inicialmente, começamos investigando o papel de pistas distribucionais, prosódicas e morfofonológicas na aquisição

\footnotetext{
${ }^{1}$ É professora associada da Universidade Federal de Juiz de Fora, atuando no Programa de Pós-Graduação em Linguística e no Departamento de Letras Clássicas e Vernáculas. cristina.name@ufjf.edu.br

${ }^{2}$ NEALP/UFJF ï Pesquisadores: Cristina Name ï Coordenadora; Mercedes Marcilese ï Vice coordenadora; Aline Fonseca; Aline Rodero-Takahira; Clara Villarinho e Paula Armelin.
} 
lexical por crianças adquirindo o $\mathrm{PB}$, analisando a fala dirigida à criança (FDC) e o impacto de suas propriedades, sobretudo prosódicas, na aquisição lexical e sintática. A prosódia também foi focalizada nos estudos sobre reconhecimento lexical e processamento de sentenças por adultos falantes nativos do PB. Hoje, temos um espectro bem maior de temas de interesse, decorrente tanto da evolução do trabalho, quanto da ampliação do corpo de pesquisadoras, com formações e interesses diversos. Pesquisas sendo desenvolvidas tratam de habilidades computacionais na aquisição da linguagem por bebês, focalizando dependências não adjacentes (p.ex., relações de concordância); questões de processamento relacionadas às interfaces externas e internas à gramática, incluindo atualmente os fenômenos de concordância e de foco/tópico, em L1 e L2 e a compreensão de linguagem não literal; mecanismos computacionais envolvidos no processo de categorização nos moldes da morfologia distribuída; efeitos morfofonológicos em compostos na aquisição típica e atípica de libras; pistas prosódicas no processamento de sentenças e da leitura por falantes do PB e da libras. Nos últimos anos, temos desenvolvido também um conjunto de pesquisas voltadas para o estabelecimento de um diálogo entre Psicolinguística e Sociolinguística, a partir das quais buscamos uma melhor caracterização da relação entre variação linguística e processamento e, de modo mais indireto, uma reflexão sobre a relação entre cognição linguística e cognição social.

Soletras: Quais as principais técnicas experimentais que vêm sendo empregadas nas pesquisas de seu Lab nos últimos anos?

Com bebês, temos usado a técnica de Olhar Preferencial, uma variação da técnica de Escuta Preferencial. Com crianças e adultos, usamos Escuta ou Leitura Auto-Monitorada (a partir de diferentes tipos de tarefas), Seleção/Identificação/Julgamento de Imagens ou Objetos, Produção Eliciada, Decisão lexical, dentre outras, a depender da faixa etária e do foco específico (percepção, compreensão, produção). Experimentos que envolvem tempo de reação como variável dependente têm sido programados e aplicados a partir de diferentes softwares especializados, tais como: Habit, Psyscope, DMDX, Linger, dentre outros; atualmente, em função de uma parceria com um grupo de pesquisa do PPG-Psicologia/UFJF, incorporamos também o software E-Prime a esse leque de opções. Além das técnicas mencionadas, outros recursos têm sido empregados, tais como questionários off-line, tarefas 
de julgamento de aceitabilidade/adequabilidade, tarefas de cloze e de paráfrase, etc. Recentemente, o laboratório recebeu um equipamento de rastreamento ocular, com o qual o leque de técnicas poderá ser ampliado.

Soletras: Você poderia fazer uma estimativa do total de pesquisas de mestrado e doutorado que foram conduzidas no Lab

A primeira dissertação e a primeira tese foram defendidas, respectivamente, em 2005 e 2012. Ao todo, foram cinco teses e vinte e quatro dissertações defendidas até o momento. É importante registrar também nossa forte atuação na Iniciação Científica, com mais de 40 orientações concluídas/em andamento.

Soletras: O Lab integra alguma rede de cooperação? Poderia citar outros Labs parceiros?

Temos parceria com o Laboratoire de Recherche sur le Langage (UQÀM, Montreal, Canadá), coordenado pela profa. Rushen Shi, com o Laboratório da Linguagem e Processos Cognitivos (LabLing, UFSC), coordenado pela profa. Mailce Borges Mota, com as pesquisadoras Erica Rodrigues (LAPAL/PUC-Rio) e Marina Augusto (UERJ). Contamos ainda com uma parceria com o Grupo de Pesquisa Cognição e Linguagem ï CogLin ï do departamento de Psicologia da UFJF, coordenado por Cláudia Nascimento Guaraldo Justi e Francis Ricardo dos Reis Justi.

Soletras: Além de trabalhos teóricos de interesse para a área da Psicolinguística, seu Lab desenvolve também pesquisas de interface com a área da Saúde elou da Educação? Se sim, quais?

Algumas de nossas pesquisas podem contribuir, direta ou indiretamente, para reflexões nessas áreas, como as relativas a aquisição de L1 e L2 ï oral e de sinais, processamento da leitura, processamento de concordância variável (verbal, nominal), processamento de linguagem não literal por parte de diferentes populações etc.

Soletras: Deixe uma palavra de seu Lab para os leitores alunos de graduação interessados em ingressar na área da psicolinguística experimental.

A psicolinguística é uma área de interface com a linguística, a psicologia cognitiva, a neurociência, a biologia e a inteligência artificial. Fazer pesquisa nessa área nos leva a estudar 
e a conhecer domínios que não imaginamos possíveis quando entramos para um curso de Letras. É uma área instigante, desafiadora e muito, muito legal!

Entrevista realizada em 11 de junho de 2017. 